\title{
Moral Concept: Understanding Moral Children Education, Who Has to Blame for the Young Generation
}

\author{
Chacha Ghati \\ Professor Wang Hai Ying \\ Wei Cong \\ Department of Early Childhood \\ College of Education Science \\ Nanjing Normal University \\ Jiang Su-China \\ Professor Caiping Sun \\ Institute of Moral Education \\ College of Education Science \\ Nanjing Normal University \\ Jiang Su-China \\ Halima Pembe Yahya \\ Department of Sociology \\ College of Public Administration \\ Hohai University \\ Nanjing, Jiang Su-china
}

\begin{abstract}
Moral education is an important part of children formal early-education development growth around the world. Parents are the first teacher to their children; then children are evident that they start to receive moral education concept from their parents (at home).This paper base on the observation of giving the insight details concept of moral and morality with its functions, however, the study is showing the roles that parents, teacher, school and community have to children.. There is a periphrastic question that "who has to blame for any distraction of children moral education?" The issue can be a universal problem. Sometimes parents push the blame on school(teachers) and viceversa. in the end, parents, teacher, school and community have to work as teamwork to fulfill children foundation of Education need, as well as to help children to mold their future in a decent way, morally and culturally based on moral understanding, judgment and children cognition.
\end{abstract}

Keywords: moral understanding, moral judgment, children moral cognition, moral education, teachers, parents, and Community.

\section{Introduction}

Pre-primary moral education has a lot to contribute to children personality and knowledge. children Moral cognitive, a moral judgment which leads to personal children understanding, It is the crucial part that different knowledge which children brought up with from their parents, teachers as well as the community. However,they are all capable and support children development of attitude and decisions in their daily life of childhood. They are cited with (Kızıltaş \& Sak 2018). At the same time, children can help and also solve some obstacles by themselves. That is to say, moral education on children does not need a long process of promoting the development of value along predetermined or linear scale instead it needs systematically analysis of different values and method whereby the purpose of the plan is to teach responsible decision-making about moral issues. The vivid example from Nanjing experiment kindergarten, after the kids finishing the blocking activities, or learn outside through play session here was the conversation in the class. "The teacher asked different questions about pictures which displayed on the screen (Paris tower). The tower seems to be weak because of the unstable foundation; some bricks were dislocated. Some contractors (children) did not see that problem, but only one boy saw the mistake, (fellow children) he spoke out his idea,and the idea was reasonable. 
The observation and the time that (teacher) gave children time to discuss the tower which built-in playing time it moved children, from the point of curiosity to the end of discovering, others drove them to the Ah! ). At the age of 3 years to 5years old, human personality starts to recognize the real him/her. (Gary E. ET a. 2017).

The age of when turning to early childhood moral education experience has much affect teenager-hood as long as adulthood, regarding decision making, viewing different ideas, the way of thinking. However, Erikson's psychosocial development theory contributed that environment has a significant contribution to children moral understanding as well as moral judgment (Günindi 2013; Kızıltaş \& Sak 2018). Moreover, the aim of this study is that, through the guidance of moral education, children can be inspired and motivated in doing something meaningful in their life, as such gaining respect for everyone around him/her, know how to help others, encourage others and so many. Through moral education children can grab the meaning of sensitivity. To a specific failure, she/he can find a way to overcome it, because the value will lead this child to the motivation, in moral education. Kohlberg believed that morally based on age and "wisdom" some what real-life experience and empathic identification with others.

\section{Methods}

\subsection{Research Design}

The study was qualitative research, which in any humanities studies and social science based on pre-primary education it might face some obstacles which need to be specific details when required the general information - the present study selected one class of 36 children and three teachers. In Dar Es Salaam City, Tanzania. Moreover, random three teachers and one educationist.

\subsection{Participants}

In this study, pre-primary education covers 4 to 6years old. Moreover, the research conducted over 14 weeks, a period of the academic year, in the middle of April 2017 to early August 2017. The participants were between 4 and 45: children, teachers, and educationist. The control group and the observation group were not the same, in the meaning that, children range between 4 to 6 years. Moreover, teachers ranged from 24 to 45 years old. The observation group had been in pre-primarly education for two years, but some children were the third year of studing, and this was because of the understanding ability.

\subsection{Data-collection tools}

Data-collection tools used in this research were the researcher notebook, pen, to note down what was going on in the class and outside the class in break time and playing time. Question guide was developed to ask teachers for curiosity - this question developed by expert opinion, view, and comments about pre-primary education in Tanzania. That can give a clear picture of the picture and express feelings, understanding about pre-primary Education.

\subsection{Data-collection process}

The observation commenced in April 2017 and ended on Early August 2017. One of the researchers included as an observer. When they arrived at school every morning, they greet their teachers with a smilling face, fellow children, school workers who are not teachers, some children met their cousnis who are in the primary this is because Brook House Kindergarten is affiliated with Sunrise primary school. After greetings every child go to his/her class where they do meet another teacher whom they greet and handle the homework that was given in a previous day, the teacher will check the home work, if is okey then a child will be allowed to have her/his sit, and if the homework is not done the teacher is obligated to ask the child why she/he did not finish the homework and why did the parent did not sign as the symble of teacher and parents working together.

\section{Results and Discussion}

The result shows that parents, teachers, and community have to work as teamwork to fulfill children foundation of education, as well as to help children to mold their future in a decent way and morally and culturally. Highly, Children do what parents/guardians/ elders do, and not what tell them to do. However, Pierson (2013), "Every kid needs a champion," she said that always children do not learn from the people they do not like. It is clear that children do what they see is right for them after experiencing the feedback from parents, teachers, or other people do or say. The bellows are some result and different discussion perspective from the community towards children moral education and who has to blame for destroying that purity of them.

\subsection{Parental part to towards children morally}

Parents are the first educators before anyone from outside such as teachers at the school, elders from churches, mosques, society, and other organizations. The notion of Parent being the first teacher it because when a child is born the first place to be is at her/his mother's hand then father, siblings then others. 
In this case, parents should guide, appreciate, and monitor at the same time support their children at whatever way they are doing in a directive way of love, ethical behavior, manner, humanity, freedom, kindness, humbleness and all related. The point that parents are very first roles models for their children, where these children can adopt from, also learn some skills. Peter L. et al. (2003). states that children can learn from their parent's actions. That is to say; parents have to be a positive role model and behave as they would like their children to be or to act. Parents must mould the moral norms as prescribed by their society that they want the foundation first learner to adopt. cited by Kwadlangezwa (2006). Parents also have to teach their children how to overcome the frustration and disappointments. Let's take an example if a child lie, push others or cry from this situation; parents have to make sure that the child understands why doing all those actions is wrong. At the sane time, her parents have to teach their children how to make compromises and negotiate. Pringle (1997) states that if parents are to claim to be the first moral educators to their children, Then, they must know how to do more than to give out their own opinion in the hope that their children will agree with them direct. Parents have to be smart especially in thinking capacity about the responsibility they have as moral educators and must act in a way that will benefit the moral status of the child. Cited by Kwadlangezwa (2006). Parents have a great responsibility to make a choice and sometimes to set an example for their child; they have to select and guide them from what is right, how good is it? What is terrible, how bad is it? What is right or wrong? Parents have to produce confident, and compassionate to their children. Parents are the most influential people in the whole process of children learning about morals. Aardweg and Aardweg (1990) say parental attitudes and behavioral responses to right and wrong, good and evil, acceptable and unacceptable, set the tone and direction of the child's moral cited by Kwadlangezwa (2006). Parents are an essential part of the school in the sense of being active in their children's learning experiences and always there for them, help them and to ensure happiness to their children at school.

\subsection{Teachers towards children moral education}

From the beginning teaching professional were counted to be a very highly respectable and were expected to be morally upright individually with the best character. Teachers are the one who has a big responsibility of teaching respect to their students. As it was till now, teachers are one of the essential element roles in daily life such as honesty, truth, humble to each other, compassion, respective, helper, encourager, and humor. From experience, teachers have to teach a child proper character. The teacher has to interact with children respectably and directive ways that from what the teacher is teaching then children can learn from their teacher, as we are aware that children are brilliant on learning from adult's action, such as commands, decision making as well as choices. Researcher Lumpkin (2008), states that the teacher was counted to be one of the integrity of people in the world; the teacher has to behave in useful ways, such as keeping promises. When this held up to public scrutiny- teacher integrity is viewed as a morally sound model for children to follow. Let's take a simple example of the physical exercise teacher whenever he/she demonstrate something in the ground-play in a very kind and humble way all children will do the same way. Here is where comes the meaning of integrity that can be referred to the doing what is right, even when it would be easier to do something that is personally more beneficial. It is imperative that teacher education student not to rationalize their unethical behavior and instead to use moral-reasoning process when making decision Lumpkin (2008). Once Pierson educator (2013) a teacher for 40 years, she heard a colleague say, "they do not pay me to like the kids.' Moreover, Rita response: 'Kids do not learn from people they do not like.' Here we can sense the power of children and teachers connections.

"However In 1916 Democracy in Education John Dewey work. He did not agree with the system that teacher as to be free in the providing the freedom and their education system. From that point, Dewey believed that democracy is suitable for corrective ideas for the obstacle. I agree with Dewey that public school system has to organize in such a way that every teacher has some regular and representative in his/her perspective way in which he or she can judgment upon matters of the importance of educational side. With the assurance that this judgment from teacher ideas will somehow affect the school system, and we cannot talk about kindergarten without including children,"

Dewey, Democracy in Education, 64. As cited by Melia L. Nebeker (2002).

Tanzanian context, in somehow teacher, is the one who has a significant impact on children moral education. The Tanzanian community believes that teachers are playing a big part in their children education. The role of teaching children good manners, how to be the right person to everyone, the sense of humor to other children and elders, feel sympathy for others, being emotion, what is right and what is wrong, how to do it, when to do it, where to do it and with who to do that.

\subsection{School towards children moral education}

School as the essential institution also has a significant task to do with children in the term of molding them morally. The school has to make sure that the environment where these children are playing has to be safe. The school has to be aware of needs for children on the playing field, like playing ground, studying rooms, art room, dancing room, and all 
another related environment that children like to play in the learning process. The atmosphere makes children love what they see (see on TV might able to be in practice), what they can associate with, what they can learn, what they hear. Gradually this kind of environment makes children have natural love from what they are surrounded with. No one has to teach them how to love, but in the real sense he or she can hear and do as teachers and parents want them to do. Children themselves naturally they can associate from the environment, they can learn from what they do, what they see, what they hear, what to practice and what they think is right at the moment. Learning from their own ability has a significant difference in determining from once ability (teachers, parents, and society in general). There some various questions which are necessary as a school to be aware of it, such as, the environment where children playing "is the space enough for all of them," "what about the material for playing are they enough?",

But also what do these children think about this environment. Tohill \& Radich (2011). Morally school environment has an impact on children learn.

\subsection{Community perspective towards children morally}

We value truth, freedom, and human rights as well as children rights. As a community, the value to children potentially has to be observed to every community member. Bases on a different aspect of understanding children, society can help teachers and parents to shape children regarding language. Respect everyone regardless of their ages and culture. However, the community can play a part in making children develop a moral situation of being truth every day, integrity, honesty and goodwill priorities in public and private life. Early childhood educators, creating a 'sense of community,' in which it is an essential part of children education. $\mathrm{O}$ the same meaning, children have to feel that they do belong to a place where they are valuable. On the same time, Children learn about themselves and construct their own identity within the context of their families and communities' (DEEWR, 2009, p. 20) cited with NQS PLP eNewsletter No.47 2012.) Small connections between children and community mean a lot of children learning and moral understanding. Community to engage children in outdoor activities with other members out of his/her own family, participating in other local community, this can lead day-to-day connections which may be more important than they just being with a teacher at the school, parents at home and school environment. It is essential that the community provide small training for children according to their culture which can make children ready for daily life selfdevelopment, at the same time parents as to be connected appropriately to their children.

\section{Who has to blame for children moral education their living community?}

Moral education to children starts at home where parents are the first teachers for their children, here every sector in one way or another trying to express how parents can fall to blame for their children moral education experts are telling their experience as David Moore, an education consultant and former senior schools inspector said below: "If you go into any shopping area on a Saturday, and you watch parents interacting with their youngsters, you can see why the youngsters behave the way they do - they model the behavior of the adults,"

This show how parents are treating their children improperly by thinking that is love for them. On the other hand, the way to be strong or to be respectable with others is to show them how can one fight back or defend oneself back, as Christine Blower, general secretary of the National Union of Teachers, said:-"Some parents tell children that if another pupil in the playground has hit them, they should hit them back nexttime." She continues to argue that "Of course that will not be, for the most part, the discipline and behavior policy that operates in the school. There are fundamental misunderstandings or differences of values."

It makes it very difficult for us (teachers) to shape the children in the right way, though the same teacher might hold the position of being parents too. Some children might be challenging to break the bridge between us (teachers) because they learn from home what their Mother/Father taught them is correct. Here Blower added that "The difficulty for us in schools is to make the bridge so that those parents who might have values at variance with what the school is trying to go into the values."

Every child, according to where he/she was born or raised up from, they have all equal and right to receive their Potential and at the same time irrespective from their parents social class that we in too. On the other hand, parents have the responsibility of teaching and care for their children more than anyone, from http://www.dailytrust.com.ng/daily/home-front/43911-moral-decadence-amongst-youth-who-is-to-blame state that, "Parents are responsible for training their children and teaching them compassion, respect as well as acceptable do's and don'ts in line with societal values and religious dictates. As such, they become responsible for the action or inaction, behavior and attitudes of their children towards others from childhood to maturity. If a child behaves well, people conclude that the child is from a disciplined home and if they behave otherwise, people fault the parents for not properly training the child. You hear people complain "didn't your parents teach you this?" or "didn't your parents teach you that?" 
Tanzania parents nowadays they are not doing what is supposed to be for their children, our school is day scholar kindergarten, and here there are two choices on sessions where some children went back home after the morning session, whereby most of the lessons are learned already. The second session is where the children went back home at 4 pm. It because most of their parents come back from work at that time. In the weekends I meet with different children at shopping malls, beaches, church, somehow in public transport. The way parents do treat their children; it is not how it supposed to be.

Said Madam Omega the head of Brookhouse international kindergarten and she continue below: "You might see children behave in a very disrespectful way but parents they took no action to their children habit. Most parents claim to live/raise their children in a modern way.

However, as I see a modern way without respecting, without manner to everyone, without value, without fearless, without sympathy, without passion, without smartness as well as culture is useless. However, at the same time, parents are mostly blaming teachers that we do not teach their children good manner of how to behave at home and to other outsiders. Teachers are not the only people who are supposed to blame for anything, even though we are the one who shapes this children's future in opening their mind in academically but we need big help from these children parents. That is why in our kindergarten decided to choose that every child has to come with his/her snacks, to avoid the unnecessary grievances from their parents about uncleaned food from the school, though we still have lunch for everyone in the school. I thought that most of the parents they need to reduce their pride and let us do our job. What they have to do is back up us in every step of their children learning the process."

The contradiction that every group is trying to explain the other what they can do to shape the future of these children. At the same time to make these children be an excellent product in days to come.

Figure. 1. Shows how children can associate with three dependable critical pillars: - Parents, Community, and Teachers.

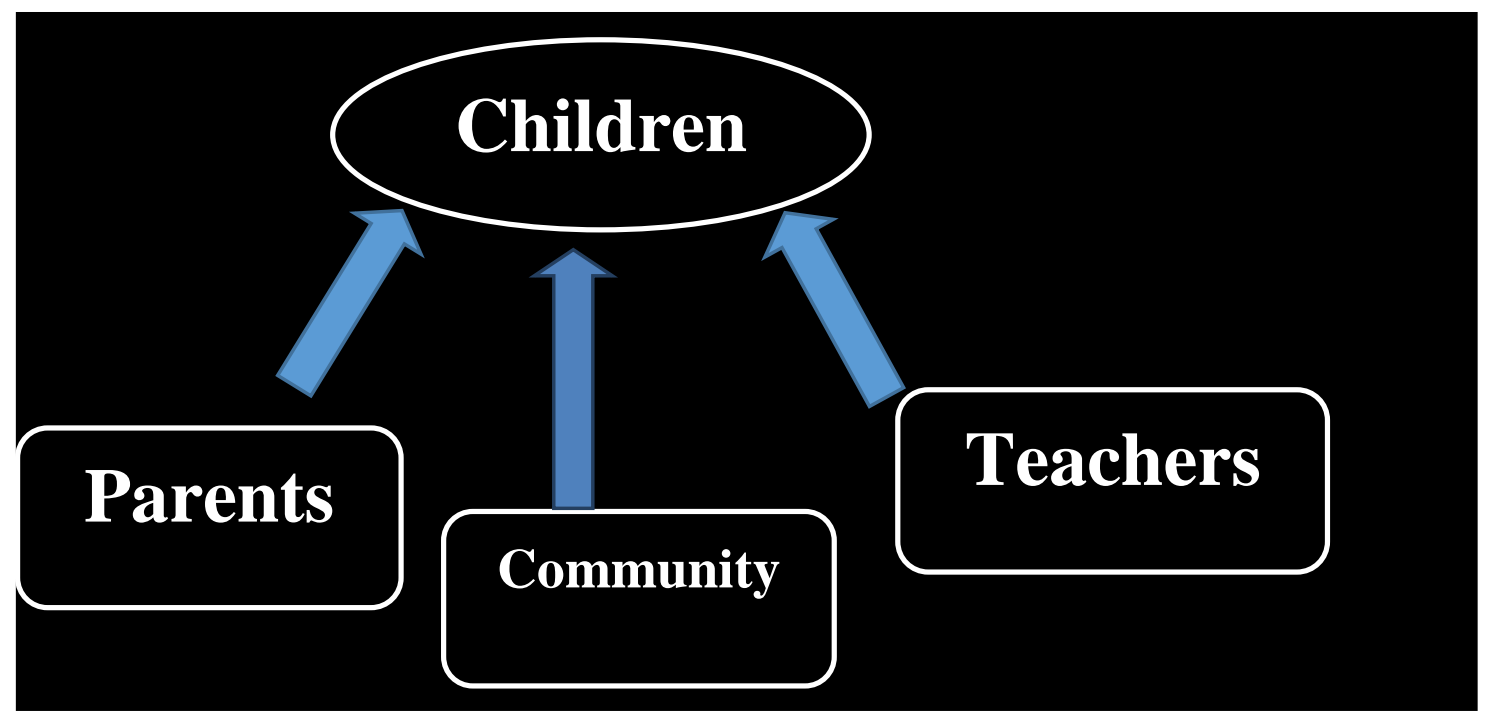

The figure above shows clearly that these three pillars are very important to each other. Parents cannot work alone; teachers cannot work alone as well as a community where children are dwelling. Parents and teachers have to be best friends to produce what is best for their little ones. Community plays a big role in making sure that they shape any child according to their surrounded culture and help them to grow morally.

\section{Conclusion}

Parents are the pillar of the family, and they do have all rights to make crucial decisions live for their children. It is to say their responsibility and under obligation to provide essential needs to support their children in primary care, spiritual, emotional and physical all these are a big help to their children regarding mold them morally. It makes parents understand that the point of pre-occupied for children is something that parents should want to implant in the minds of their children. A parent might have the question of what exactly do they implant in the minds of their children? If not materialism and the world, what do they teach them?

However, parents, teachers, and a community have to come as one united group work as a team-work. Parents have to play a part of helping teacher give them confidence and help their children so that children could receive equal education whereby could be no place to lay on, in the meaning of equality and inequality. 
At the same time parents also has rights to build boundaries for their children's behavior and stay with those which are profitable. Both of them they have to make choices, and they have to decide for them also setting a good example to their children and spending precious time with children so that children could feel the presence of their teacher, parents, community and value the moment.

At the same time, children will learn meaning bond of love of family and love from their teachers as the society. Bouster (2009) from https://www.theguardian.com/commentisfree/2009/a pr/05/children-social-skillsparenting, states that."Schools do not exist in a vacuum. If they are to succeed, then more parents have to put more effort into their parenting and into creating the conditions in which their children come to school ready and willing to learn." The only school cannot be the right place to right the wrongs of the whole society and teachers cannot take as the only part of blaming for children moral education. It is undeniable truth that when children live in a specific environment, they do learn what they are in to: take this an excellent example of a child lives and learns. If a child lives with criticism, he/she learns to condemn. If a child lives with hostility, he/she learns to fight. If a child lives with fear, he/she learns to be apprehensive. If a child lives with pity, he/she learns to be sorry for himself. If a child lives with jealousy, he/she learns to feel guilty. If a child lives with encouragement, he/she learns to be confident. If a child lives with tolerance, he/she learns to be patient. If a child lives with praise, he/she learns to be appreciative. If a child lives with recognition, he/she learns what justice is. If a child lives with acceptance, he/she learns to love. If a child lives with honesty, he/she learns what truth is. If a child lives with security, he/she learns to have faith in himself. If a child lives with friendliness, he/she discovers that the world is a beautiful place to live. If a child lives with the spiritual, he/she learns to have faith in God.

\section{Declarations}

\section{Competitive interest}

The study base on the innovation early childhood education of Tanzania, from the learning experience of Chinese preschool education, co-completion involve rather than grabbing new technics of educating young children. No competitive interest.

\section{References}

\section{Journal Papers/Book:}

Angela Lumpkin (2008). Teacher as a role model, teaching character and moral virtues.

Dewey, John. (1916). Democracy and Education. NY: Macmillan Publishing Co., Inc.

Emine Kızıltaş \&Ramazan Sak (2018). Integrating field-trip activities with other activities in the preschool curriculum: its effects on the preschoolers' social-emotional skills.

Gary E. Bingham, Hyun-Joo Jeon, Kyong-Ah Kwon \& Chaehyun Lim (2017). Parenting styles and home literacy opportunities: Associations with children's oral language skills.

Melia L. Nebeker (2002). The Teacher and Society: John Dewey and the Experience of Teachers.

Peter L. Benson, Eugene C. Roehlkepartain, and Stacey P. Rude (2003). Spiritual Development in Childhood and Adolescence: Toward a Field of Inquiry. Applied Developmental Science, Vol. 7, No. 3, 205-213.

Pringle K (1997). The needs of children. London, Hutchinson.

Slhaynes Kwadlangezwa (2006). The Role of the Family in the Moral Development of the Foundation Phase Learner. Department of Educational Psychology and Special Education, Faculty of Education at the University of Zululand. Socio-education at the University of South Africa.

Van den Aardweg EM \& Van den Aardweg ED (1990). Dictionary of empirical education/educational psychology. Pretoria: E \& E Enterprises.

Yunus Günindi (2013). An Evaluation of Social Adaptation Skills of Children with and without Preschool Education Background Based on Their Mothers' Views.

Cites.

Department of Education, Employment and Workplace Relations (DEEWR). (2009) Belonging, Being and development. ZERO TO THREE. National Center for Infants, Toddlers, and families. Washington, DC. Engagement. Luke Touhill \& Judy Radich (2011).Learning environment Workshop at Campbell street childcare and early education center.

http://family.findlaw.com/emancipation-of-minors/how-long-do-parents-legal-obligations-to-theirchildrencontinue.html.

http://www.dailytrust.com.ng/daily/home-front/43911-moral-decadence-amongst-youth-who-is-to-blame.

https://www.psychologynoteshq.com/kohlbergstheory/ psychology notes 2016.Kohlberg's Theory.

https://www.theguardian.com/commentisfree/2009/apr/05/children-social-skills-parenting.

https://www.theguardian.com/education/mortarboard/2010/oct/13/parents-blamed-for-bad-behaviour.

National Quality Standard Professional Learning Program e-Newsletter No.47 2012. The community of Moral Development. Parents to Their Children in the 21st Century.

Rita Pierson 2013 Rita Pierson: Every kid needs a champion | TED Talk | TED. https://www.ted.com/talks/rita_pierson_every_kid_needs_a_champion. 